\title{
Experimental study of the aircraft air cycle machine rotor dynamics on gas foil bearings
}

Igor Valerevich Tishhenko ${ }^{1, a)}$, Vitaliy Stanislavovich Nikolaev $1, b)$,

Vladislav Ivanovich Merkulov ${ }^{1, c)}$

${ }^{1}$ Bauman Moscow State Technical University, Moscow, Russian Federation

a)iv.tischenko@bmstu.ru

b)vs.nikolaev.bmstu@gmail.com

c) vim1935@mail.ru

\begin{abstract}
In this paper the results of the experimental research of the dynamics of the rotor of a four-wheeled aircraft air cycle machine on gas foil supports under conditions of vibration. The description of the experimental unit, measuring system, and methods of results processing is given. The rotor of the turbomachine is mounted on compliant gas foil journal bearings of the second generation. The rotor speed varied from 20000 to $32000 \mathrm{rpm}$. The cooling turbine was exposed to broadband random vibration with a mean square value of Vibro-acceleration up to $5 \mathrm{~g}$. The influence of vibration load level, air supply temperature, amplitude-frequency characteristics of the turbine cooler case, and vibration equipment on the rotor dynamics was assessed.
\end{abstract}

Keywords: turbomachine, air cycle machine, cooling turbine, gas foil bearings, vibration.

\section{INTRODUCTION}

The object of this study is a four-wheeled aircraft air cycle machine (ACM) with 2 turbine stages, compressor stage, and fan stage. The ACM rotor is supported by compliant journal gas foil bearings and spring thrust gas foil bearings. Currently, work is underway to modernize the radial bearing units: the transition from multipad gas foil bearings to compliant bearings. The modernization aims is to increase the vibration resistance of the ACM by using a new journal bearing design. Experimental research was carried out based on the PJSC NPO "Nauka".

The rotor of a high-speed turbomachine on gas foil bearings operates under conditions of complex loading from nonlinear reactions of bearings, forces arising in non-contact seals, and gas forces from the main flow parts. With the development of computer technology, the means of numerical investigation of gas foil processes in flow parts of turbomachines (Grishin, 2015) and volumetric machines (Voronov et al 2015, Ivlev et al 2015) are increasingly being applied. Currently, many works are describing the methods of calculation and experimental research of gas foil 
bearings on laboratory stands of bearings of various designs, for example, in the works (Hoffmann and Liebich, 2017; Lee et al., 2004), as well as many others, but there is not much information about field tests or in actual operation. This kind of work can include a study of the stability of the forced induction of diesel engine turbochargers (Keun Ryu, Zachary Ashton, 2017). In Russia earlier similar work was carried out with bearings of the 1st generation (Peshti, 1993), it was used a numerical simulation of operating parameters of bearings of the 1st generation (Merkulov et al., 2018; Galimov et al., 2018), and modern constructions tested on laboratory installations (Temis, 2011).

The development of the theory and practice of vibration studies of the dynamics of high-speed machines contributes to a further increase in the reliability of individual systems and the entire aircraft as a whole. An example of modern research in this area is the study of Akulenko et al., 2017.

A reliable and objective conclusion about the reliability achieved as a result of the modernization of the system is given by modern research in the field of reliability theory (Pavlov, 2015; Sadykhov, 2016). The study of turbomachinery on gas foil bearings is an extremely important area due to its wide range of applications, including space cooling systems (Devkov, 2016).

\section{DYNAMIC PERFORMANCE ANALYSIS}

One of the stages of the upgrade is to evaluate the actual load on a journal bearing. The evaluation problem is related to the aspiration for vibration isolation of support units from external influences. Vibroinsulation is achieved due to the elasticity and viscosity of the body materials, the design of attachment units, and the use of shock absorbers. Besides, when performing vibration tests, the ACM is attached to a vibrodynamic test bench using special accessories that have their frequency characteristics.

\section{Dynamics}

In the case of a vibration bench that simulates the external mechanical action that occurs during flight and take-off/landing, the rotor must pass through a chain of dynamic links before the dynamic action can affect it.

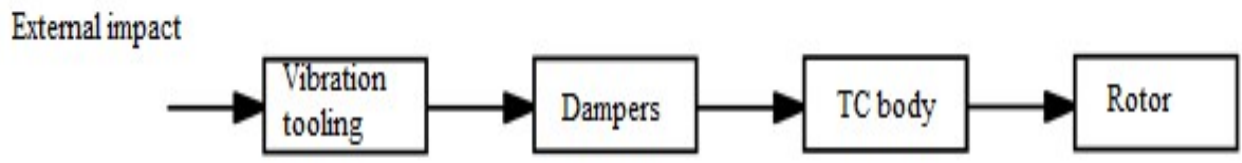

Figure 1. Dynamic air cycle machine Vibration Test Scheme. 
To assess the impact of external factors on the dynamics of the ACM rotor, it is necessary to study the dynamic characteristics of each link.

\section{Gas Foil Bearings}

The journal gas foil bearing is a 2 nd generation compliant bearing with an antifriction-coated foil and vibration-damping bumps. The thrust gas foil bearing is a sevenpad bearing with lining springs. A diagram of the journal bearing and a picture of the thrust bearing are shown in Figure 2 .

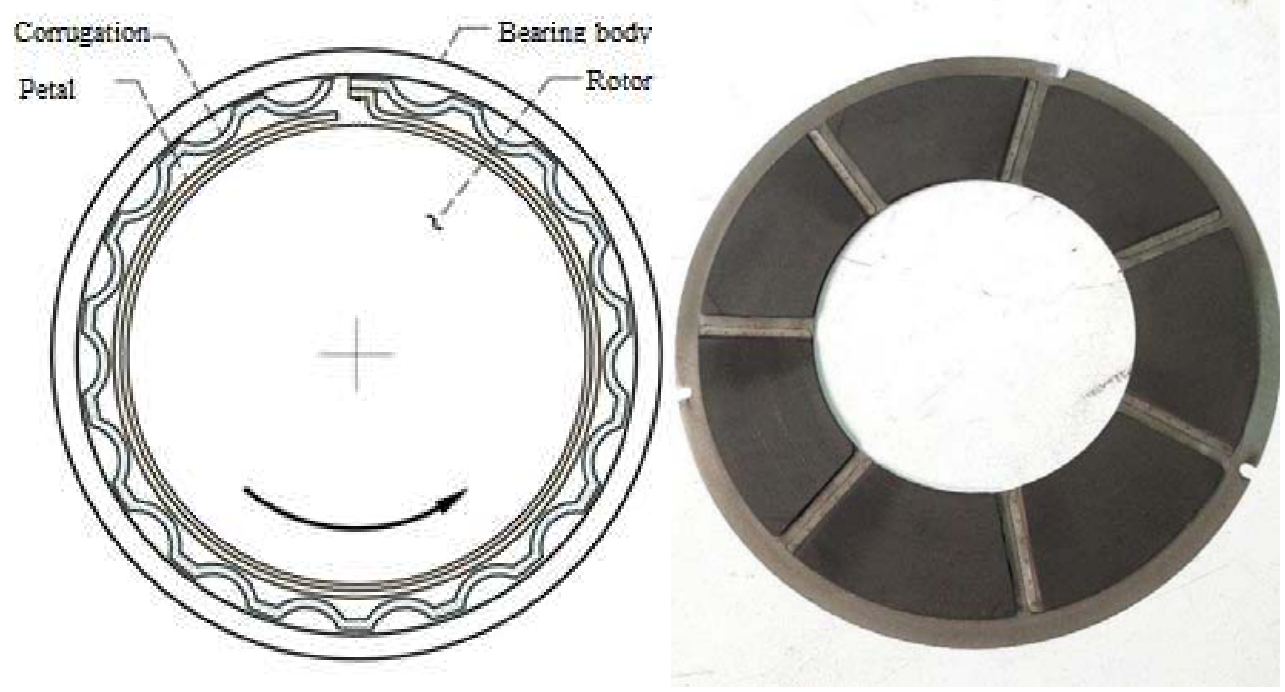

Figure 2. Design of gas foil bearings (a) schematic of a journal compliant foil bearing, (b) photograph of an thrust bearing

\section{The frequency response of the BODY}

An important transmission link between the aircraft fuselage and rotor is the ACM body. Its elastic and damping properties significantly influence the rotor dynamics. Also, various dampers are often installed between the ACM mountings and the power elements in the fuselage.

Using the finite element method, the amplitude-frequency response (AFR) and phase-frequency response (FFR) of turbine and fan radial bearing housings were calculated in the software ANSYS relative to the attachment systems of the ACM.

To verify the calculation, the same AFRs were experimentally obtained by the scanning frequency method. The results of the calculation were confirmed, and the experimental data were supplemented with the calculated FFR. The obtained calculated AFRs are shown in Fig. 3. 


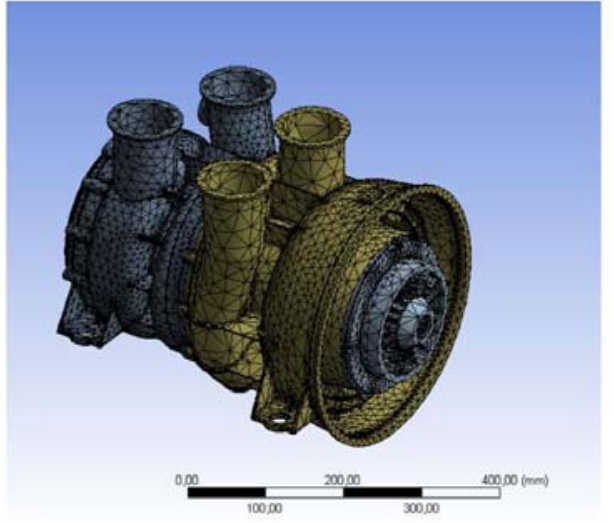

(a)

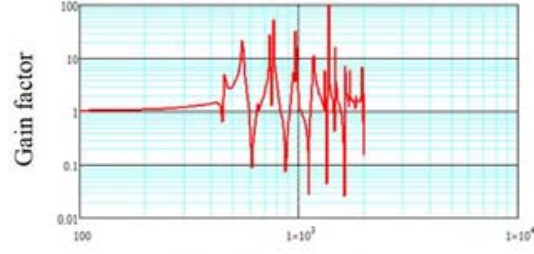

Force frequency, $\mathrm{Hz}$.

(b)

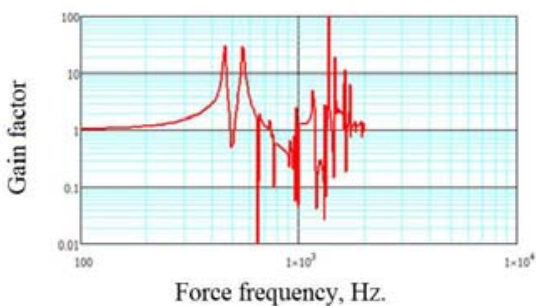

(c)

Figure 3. (a) Finite element model of ACM casing (b) turbine side bearing casing AFR, (c) fan side bearing casing AFR.

\section{Vibration}

A broadband random vibration with the imposition of polyharmonic vibration according to section 8 of the QR-160D qualification requirements for helicopters was chosen as the main external influencing factor. These conditions are considered the most loaded for a turbomachine of this size. A suitable analog of the object-application is a heavy transport helicopter. Sources of harmonic influence on the helicopter are 1st and 2nd harmonics of the speed of the main screw 17 and 34 $\mathrm{Hz}$ accordingly, speed of the main gear of approximately $137 \mathrm{~Hz}$, and frequency of the free turbine of $\approx 182 \mathrm{~Hz}$. The spectral density of power of the broadband random vibration acceleration is $0.02 \mathrm{~g}^{\wedge} 2 / \mathrm{Hz}$ with an inclination of minus $3.0 \mathrm{~dB} /$ octave after $300 \mathrm{~Hz}$. The spectrogram of the most loaded test mode is shown in Figure 4.

The method of scanning frequency with a scanning speed of 1 octave/min and amplitude of $1 \mathrm{~g}$ was used to remove the AFR. Measurements were made at different rotor speeds and different ambient temperatures surrounding the rotor. 


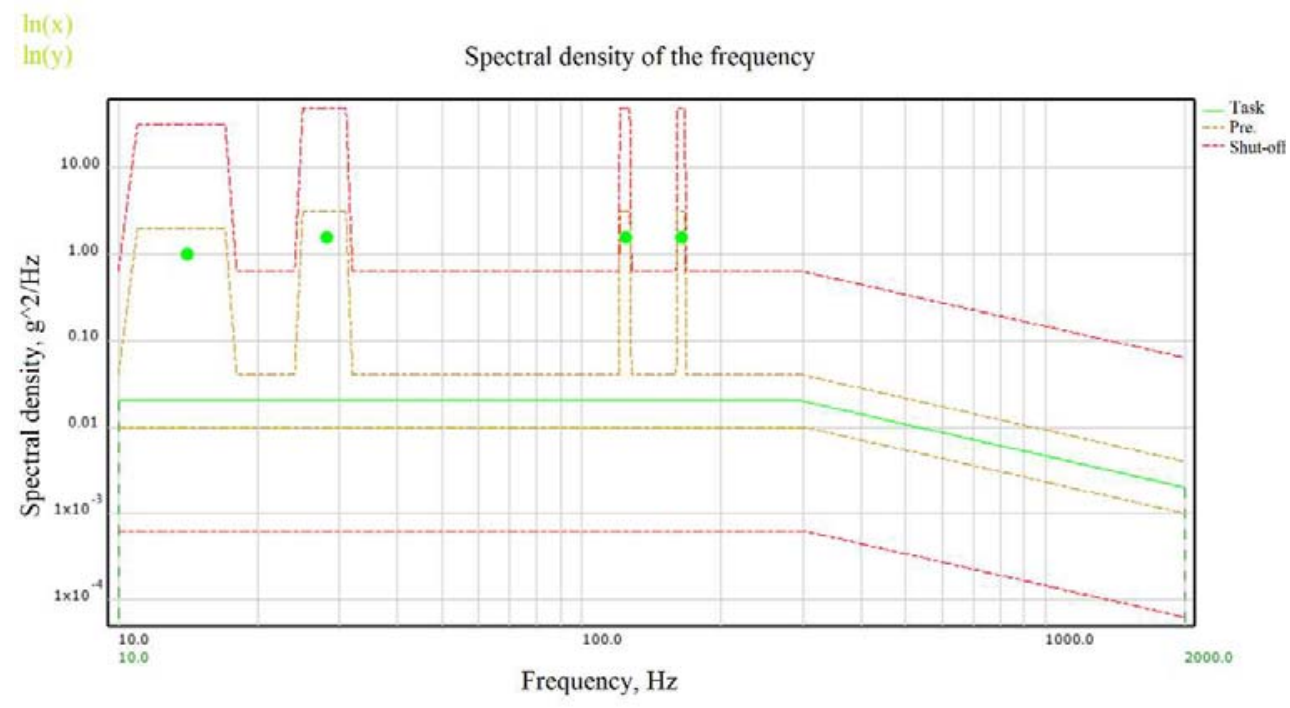

Figure 4. Spectral characteristics of the load mode.

\section{Experimental test bench}

The experimental test bench consists of a vibration test bench with its control system installed on it, air supply pipes, electric furnaces, and a data acquisition system. Data on air pressure and temperature at various points of the working path, data on the rotor speed, and data on the movement of the ACM rotor relative to the body were collected in real-time. Measurements of movements were made in two mutually perpendicular planes, perpendicular to the axis of rotation in two points: on the fan wheel hub and the outer diameter of the rotor heel. Eddy current sensors were used to measure movements. The motion sensors were pre-trimmed for maximum accuracy. Data from all sensors were received in real-time by L-Card's ADC and then transmitted to the computer. 


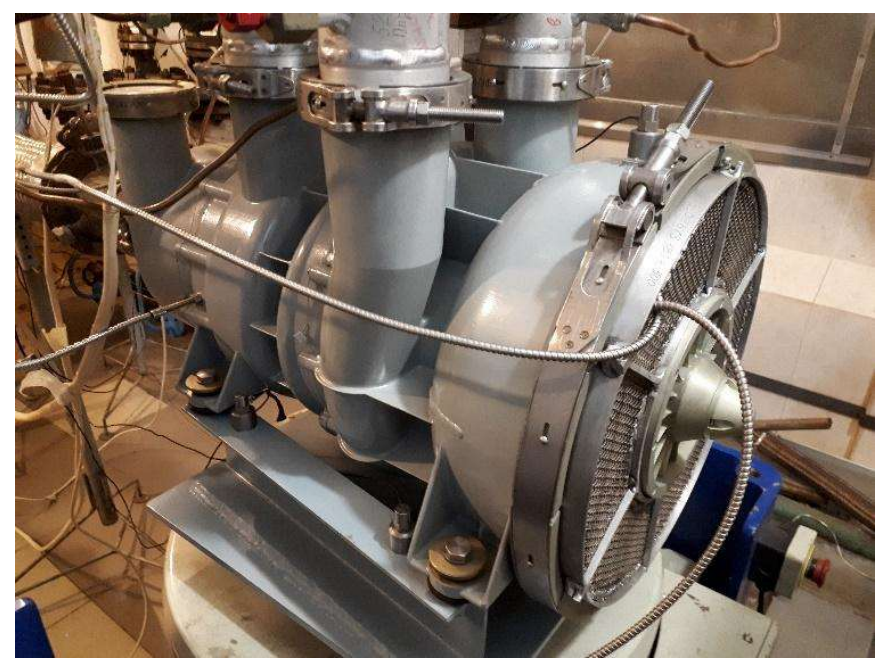

Figure 5. Appearance of the ACM mounted on the vibration stand

\section{Processing of results}

The results were processed using the Fourier transform in the frequencytime domain. The sampling frequency of rotor vibrations was $100 \mathrm{kHz}$. Hann's spectral window was used, the width of the window was $2^{\wedge} 15$ samples (about 32.8 thousand points), the overlapping coefficient of windows was equal to 0.1 .

Figure 6 shows the frequency spectrum of rotor TC vibrations in the vertical direction during the start and acceleration of the rotor ACM, as well as the free run of the rotor after the interruption of the compressed air supply. The resonance frequency of $\approx 40 \mathrm{~Hz}$, associated with shock absorbers, on which the ACM is installed, as well as the natural frequency of radial bearings of $\approx 120 \mathrm{~Hz}$ is visible. At both these frequencies, the energy of the oscillations caused by the unbalance remaining after the high-frequency balancing of the rotor is dissipated. During acceleration and coasting, the rotor vibrations resonate with the bearing vibrations. 


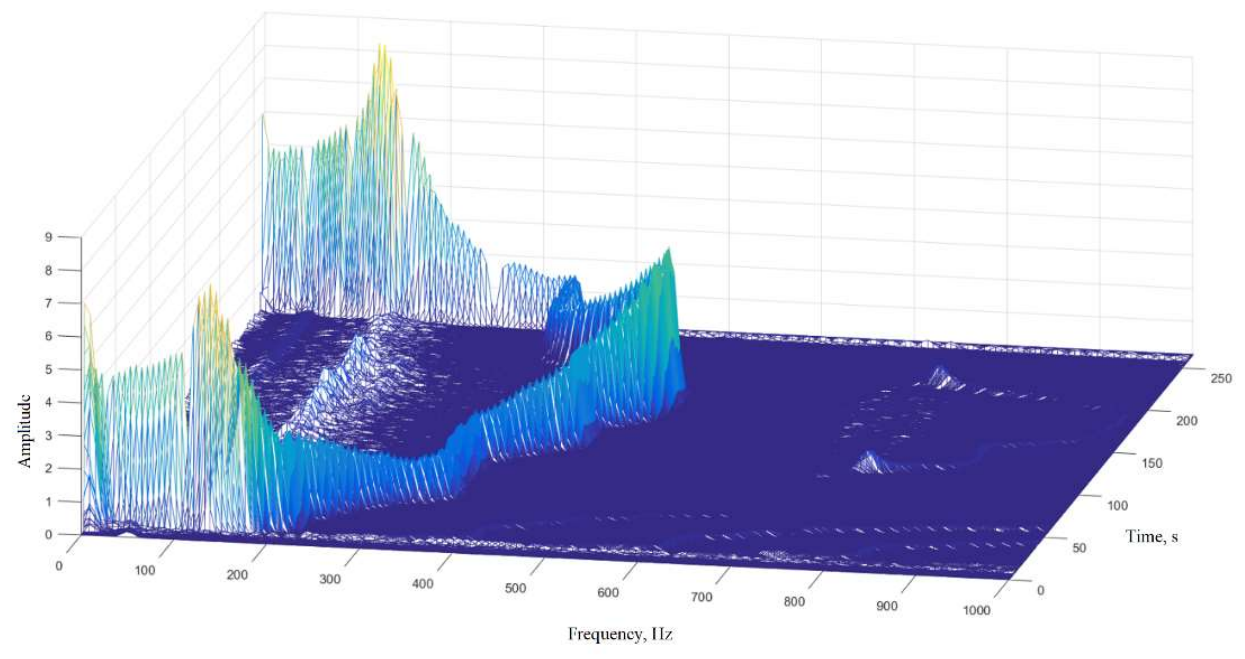

Figure 6. Air cycle machine braking acceleration diagram. For the frequency analysis, we used Fourier transform with Hann's window, window width $2^{\wedge} 15$ samples, window overlapping factor 0.1 vibrations.

Figure 7 shows the vertical response spectrum of the ACM rotor to a sinusoidal force deployment. Here, the response of the rotor to its resonance frequency is also observed.

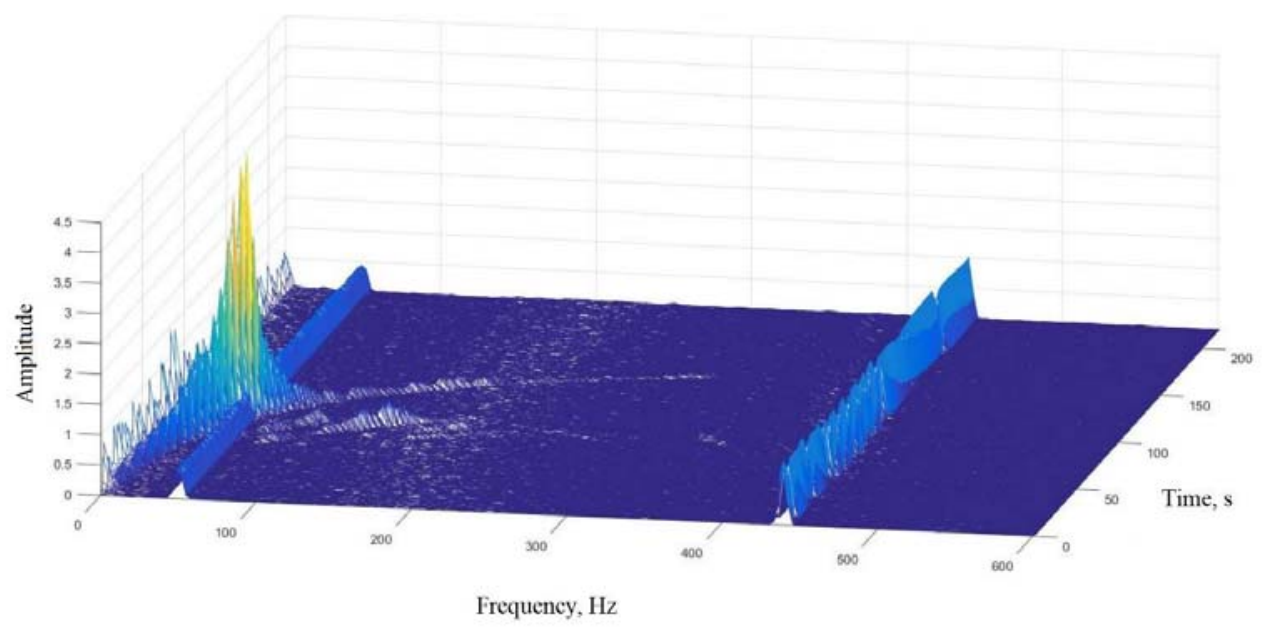

Figure 7. Diagram of rotor ACM reaction to $1 \mathrm{~g}$ amplitude harmonic exposure (AFR removal). For frequency analysis, we used the Fourier transform with Hann's window, window width $2^{\wedge} 15$ samples, window overlapping factor 0.1 . 
Figure 8 shows the trajectory of the rotor in the fan bearing. The average vibration amplitude of the residual unbalance was $25 \mu \mathrm{m}$. This value is almost the same for the direction along the $\mathrm{X}$-axis and $\mathrm{Y}$-axis, which indicates the high load carrying capacity of this bearing.

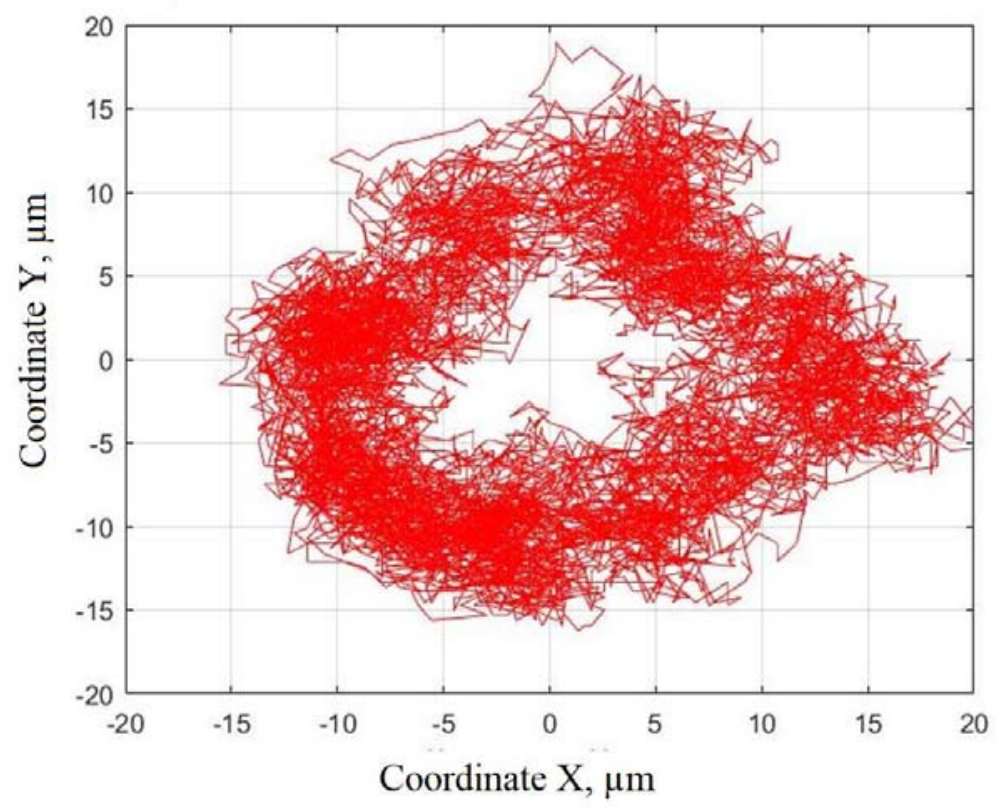

Figure 8. Trajectory of the TC rotor relative to the fan bearing housing.

\section{CONCLUSION}

In the given work the experimental research of dynamics of a rotor of an aircraft four-wheeled air cycle machine on gas foil bearings is executed. In the course of experimental research, the dynamic characteristics of the air cycle machine case were obtained, confirming the correctness of finite element calculation, and dynamic characteristics of the rotor reaction to external influences.

The data obtained during the experiment will be used to build a mathematical model of rotor dynamics.

\section{REFERENCES}

1. A.V. Devkov, A.A. Kishkin, N.A. Lavrov and F.V. Tanasienko, 2016. Analysis of efficiency of systems for control of the thermal regime of spacecraft. Chemical and Petroleum Engineering, Vol. 5.

2. Yu.A. Grishin, V.N. Bakulin, 2015. Numerical investigation of flow in a centrifugal compressor. Journal of Engineering Physics and Thermophysics, Vol. 88, 5, $1275-1279$.

3. R. Hoffmann, R. Liebich, 2017. Characterisation and calculation of nonlinear vibrations in gas foil bearing systems - An experimental and numerical investigation. Journal of Sound and Vibration, 412, 389-409. 
4. Keun Ryu, Zachary Ashton, 2017. Oil-Free Automotive Turbochargers: Drag Friction and On-Engine Performance Comparisons to Oil-Lubricated Commercial Turbochargers. Journal of Engineering for Gas Turbines and Power, Vol. 139.

5. Lee, Y.-B., et al., 2004. Dynamic characteristics of a flexible rotor system supported by a viscoelastic foil bearing (VEFB). Tribology International, 37, $679-687$.

6. I.V. Pavlov, 2015. The Lower-Bound Estimate of Reliability Based on the Results of Accelerated Tests. Journal of Machinery Manufacture and Reliability, Vol. 44, 3, 257-262.

7. G.S. Sadykhov, I.A. Babaev, 2016. Computations of the Least Number of Objects Necessary for the Cyclical Reliability Testing. Journal of Machinery Manufacture and Reliability, Vol. 45, 3, 239-246.

8. L.D. Akulenko, V.G. Bajdulov, D.V. Georgievskij, S.V. Nesterov, 2017. Evolution of natural frequencies of longitudinal vibrations of a bar as its cross-section defect increases. Mechanics of Solids, №6, 708-714.

9. V.I. Merkulov, V.S. Nikolaev, Yu.I. Matveev, I.V. Tishhenko, 2018. Equation solution of the gas lubrication on the profile petal surface. Marine Intellectual Technologies, T. 2, 4 (42), $150-154$.

10. Peshti, Yu.V, 1993. Gas Film: Textbook for universities. Publishing office of BMSTU. Moscow, p.381.

11. Temis, Yu.M., Temis, M. Yu. \& al., 2011. Rotor in gas bearings dynamics experiment-calculated investigation. Bulletin of Samara State Aerospace University, T. 27 №3.

12. V.A. Voronov, V.P. Leonov testing of a scroll expander in various modes Chemical and Petroleum Engineering. 2015. T. 51. № 1. C. 33-36.

13. V.I. Ivlev, V.M. Bozrov, V.A. Voronov Testing a scroll machine in pneumatic motor-expander modes Journal of Machinery Manufacture and Reliability. 2015. T. 44. № 2. C. 120-124.

14. A.R. Galimov, V.I. Merkulov, M.N. Pokusaev, I.V. Tishhenko an assessment of the probability of failure of air-to-air heat exchangers when operating airconditioning systems Marine Intellectual Technologies. 2018. № 4-2 (42). P. 155-160. 